\title{
Composição química dos cascos de eqüinos das raças Pantaneira e Mangalarga Marchador
}

[Chemical composition of black versus non-pigmented hooves from Pantaneira and Mangalarga Marchador horses]

\author{
G.A. Faria ${ }^{1}$, A.S.C. Rezende $e^{2 *}$, I.B.M. Sampaio ${ }^{2}$, A.M.Q. Lana $^{2}$, R.S. Moura $^{3}$, \\ J.S. Madureira ${ }^{4}$, M.C. Resende \\ ${ }^{1}$ Médico veterinário \\ ${ }^{2}$ Escola de Veterinária da UFMG \\ Caixa Postal 567 \\ 30123-970 - Belo Horizonte, MG \\ ${ }^{3}$ Estudante de mestrado - EVUFMG - Belo Horizonte \\ ${ }^{4}$ Escola de Veterinária da UFMS - Campo Grande, MS \\ ${ }^{5}$ Estudante de graduação - EVUFMG
}

\begin{abstract}
RESUMO
Pesquisaram-se eventuais diferenças na composição da matéria seca (MS), proteína bruta, extrato etéreo, cinzas, cálcio, fósforo, cobre, zinco, perfil de aminoácidos e biotina entre cascos pretos e claros, de eqüinos das raças Pantaneira e Mangalarga Marchador, criados na região do Pantanal, MS, e no município de Caeté, MG, respectivamente. De cada raça foram coletadas amostras de 10 éguas vazias, não lactantes, com idade entre 5 e 10 anos, sendo que, em um mesmo animal, foram retiradas amostras das duas colorações de casco nas regiões da pinça, ombro, quarto e talão. Na raça Pantaneira, os cascos claros apresentaram maior teor de fósforo que os pretos, e os demais elementos avaliados não foram diferentes segundo a cor. Na Mangalarga Marchador, não houve diferença entre os cascos claros e pretos, quanto a todas as características estudadas.
\end{abstract}

Palavras-chave: eqüino, casco, coloração do casco, proteína, aminoácido, biotina, minerais

\begin{abstract}
Chemical composition (dry matter, crude protein, ether extract, ash, calcium, phosphorus, copper and zinc and amino acid profile) in black and non-pigmented hooves from non-lactating five-to ten-year-old Pantaneira and Mangalarga Marchador mares raised in central and southeastern Brazil was studied. In the Pantaneira breed, phosphorus concentration was higher in non-pigmented than in black hooves, but hoof color did not affect any other composition variables. Likewise, black versus non-pigmented hooves did not differ for any composition variable in the Mangalarga Marchador mares.
\end{abstract}

Keywords: equine, hoove, hoof color, protein, amino acid, biotin, mineral

\section{INTRODUÇ̃̃̃O}

Os eqüinos da raça Pantaneira surgiram, por seleção natural, na região central do estado do Mato Grosso, em áreas alagadas do Pantanal.
Nas condições adversas dessa região, desenvolveram habilidade para pastar em regiões submersas e adquiriram cascos resistentes, que suportam terrenos alagadiços durante muitos meses (Rezende, 2001). Os da raça Mangalarga

Recebido para publicação em 22 de maio de 2004

Recebido para publicação, após modificações, em 8 de dezembro de 2004

*Autor para correspondência (corresponding author)

E-mail: adalgiza@vet.ufmg.br 
Marchador originaram-se no sul de Minas Gerais e se tornaram a raça mais numerosa do país (Costa et al., 2004). São utilizados em vários tipos de esporte e principalmente no trabalho de campo, em fazendas de gado de corte e leite (Nascimento, 1999).

O padrão racial do cavalo Pantaneiro e Mangalarga Marchador recomendou que os cascos devem ser de preferência escuros (Torres et al., 1992; Associação..., 2003). Butler (1992) e Nascimento (1999), ao descreverem a coloração dos cascos, afirmaram que o pigmento escuro não melhora a sua qualidade ou resistência. Nascimento (1999) também enfatizou que não há motivos que justifiquem a desvalorização dos cascos claros em relação aos escuros, pois os dois tipos têm a mesma estrutura protéica, com a composição de aminoácidos semelhante. Comben et al. (1984) encontraram menor resposta à suplementação com biotina em eqüinos de casco branco do que nos de casco escuro, pois aqueles necessitaram maior quantidade dessa vitamina, e os efeitos benéficos da suplementação demoraram mais a surgir e foram mais discretos.

A biotina parece ser um nutriente de influência sobre a resistência dos cascos. Zenker et al. (1995), ao trabalharem com 42 garanhões da raça Lipizzaner, dos quais $90 \%$ com problemas nos cascos, verificaram que a suplementação com biotina melhorou a sua condição. Essa melhora ocorreu na linha branca, na histologia e na resistência após 19 meses de suplementação. O aumento da resistência e dureza do casco ocorreu após 19 a 33 meses do início da suplementação.

A influência da raça sobre a resistência dos cascos foi pesquisada por Spitzlei (1996), ao avaliar cascos íntegros ou acometidos de cavalos de tração, da raça Puro Sangue Inglês e de várias raças alemãs utilizadas para salto. Verificou diferenças entre raças quanto à composição de minerais. Encontrou também correlação linear entre integridade, resistência e concentração de cistina no casco e concluiu que existe diferença na composição segundo a região do casco. A muralha tem, em relação à sola, maiores concentrações de zinco, cobre, selênio, cistina, histidina e prolina e menores concentrações de ácido aspártico, glicina, tirosina, fenilalanina e lisina.
$\mathrm{Na}$ literatura consultada, não foram encontrados estudos sobre a composição dos cascos segundo a coloração e sua associação com resistência. Assim, o objetivo deste trabalho foi avaliar a composição química de cascos segundo a coloração, em eqüinos das raças Pantaneira e Mangalarga Marchador.

\section{MATERIAL E MÉTODOS}

O experimento foi realizado com eqüinos das raças Pantaneira e Mangalarga Marchador criados no Pantanal (Fazenda Rancharia, município de Corumbá, MS) e no Haras Luxor, município de Caeté, MG, respectivamente. Foram colhidas amostras do casco de 20 éguas adultas, 10 de cada raça, não prenhes e não lactantes. As éguas, com idade entre 5 e 10 anos, tinham cascos claros e pretos, foram criadas em pasto, sem suplementação de ração concentrada e receberam apenas sal mineralizado ${ }^{1}$ à vontade, em cocho coberto. A composição bromatológica e a de aminoácidos das gramíneas ingeridas nas diferentes localidades encontram-se nas Tab. 1 e 2 , respectivamente.

Tabela 1. Composição das gramíneas consumidas pelas éguas (base MS)

\begin{tabular}{lcc}
\hline Nutriente & Tifton $85^{1}$ & Mimoso $^{2}$ \\
\hline Matéria seca (\%) & 92,64 & 92,01 \\
Cinzas (\%) & 7,33 & 11,54 \\
Proteína bruta (\%) & 16.48 & 9,68 \\
Extrato etéreo (\%) & 1,64 & 1,61 \\
Fibra bruta (\%) & 6,08 & 8,98 \\
Cálcio (\%) & 0,20 & 0,11 \\
Fósforo (\%) & 0,20 & 0,10 \\
Cobre (ppm) & 7,17 & 0,78 \\
Zinco (ppm) & 66,45 & 15,14 \\
\hline
\end{tabular}

${ }^{1}$ Cynodon spp.: gramínea ingerida pela raça M. Marchador.

${ }^{2}$ Paratheria prostata: gramínea ingerida pelo cavalo

Pantaneira.

Só foram coletadas amostras de éguas com exame clínico favorável no aspecto podológico. Esses animais tinham cascos de coloração distinta nos membros anterior e posterior e, para confrontar a composição dos cascos das duas tonalidades, as amostras foram coletadas em uma mesma égua.

\footnotetext{
${ }^{1}$ Sal mineral Prodap - Equinos(Mangalarga Marchador) e Sal mineral Servsal (Pantaneira)
} 
Composição química dos cascos...

Tabela 2. Análises de aminoácidos das forragens (base MS), consumidas pelas éguas

\begin{tabular}{lccccc}
\hline Aminoácido (\%) & ${\text { Tifton } 85^{1}}^{1}$ & Mimoso $^{2}$ & Aminoácido & ${\text { Tifton } 85^{1}}^{1}$ & Mimoso $^{2}$ \\
\hline Ácido aspártico & 0,20 & 0,10 & Prolina & 0,88 & 0,25 \\
Ácido glutâmico & 0,22 & 0,15 & Tirosina & 0,43 & 1,61 \\
Serina & 1,05 & 0,77 & Valina & 0,98 & 0,00 \\
Glicina & 0,28 & 0,26 & Leucina & 0,57 & 0,00 \\
Histidina & 0,69 & 0,40 & Metionina & 0,83 & 0,55 \\
Arginina & 0,99 & 0,52 & Isoleucina & 1,07 & 0,71 \\
Treonina & 1,35 & 0,63 & Cistina & 0,82 & 0,60 \\
Alanina & 0,66 & 0,27 & Fenilalanina & 0,92 & 0,61 \\
& & & Lisina & 0,40 & 1,14 \\
\hline
\end{tabular}

${ }^{1}$ Cynodon spp.: gramínea ingerida pela raça M. Marchador.

${ }^{2}$ Paratheria prostata: gramínea ingerida pelo cavalo Pantaneira.

Antes da coleta, os cascos foram previamente lavados com detergente isento de minerais (Extram) e secos com álcool absoluto. As amostras, retiradas com torquês nas regiões da pinça, ombro, quarto e talão, foram acondicionadas em sacos plásticos identificados, lacrados e congeladas. No laboratório, em placas de Petri, foram levadas à estufa $\left(65^{\circ} \mathrm{C}\right)$ com ventilação forçada para retirada parcial da umidade e moídas em moinho de panelas de $15 \mathrm{~cm}$, modelo PFAFF.

Realizaram-se as análises de extrato etéreo (EE) sem hidrólise ácida, matéria seca (MS) a $105^{\circ} \mathrm{C}$, cinzas $(\mathrm{Ci})$ a $600^{\circ} \mathrm{C}$ e fósforo $(\mathrm{P})$ por fotometria de acordo com AOAC (Cunniff, 1995); biotina (Bi), por cromatografia líquida de alta eficiência (CLAE) em coluna RP18 e detector de UV, em cromatógrafo VARIAN série 5000, e proteína bruta (PB), com o aparelho LECO, modelo FP 528.

Para as análises de cálcio, cobre e zinco, utilizouse a técnica de espectrofotometria de absorção atômica de acordo com AOAC (Cunniff, 1995) e, para o aminograma, o cromatógrafo de fase líquida VARIAN, com detector de ultravioleta.

Usou-se o teste t pareado nas comparações entre cascos claros e pretos no mesmo animal e nas duas raças, separadamente $(\mathrm{P}<0,05)$, utilizandose 10 repetições por tratamento como se segue: cascos claros da raça Mangalarga Marchador (MMc), cascos pretos da raça Mangalarga Marchador ( $\mathrm{MMp}$ ), cascos claros da raça Pantaneira (Pc) e cascos pretos da raça Pantaneira (Pp).

\section{RESULTADOS E DISCUSSÃO}

A composição química e a composição de aminoácidos são apresentadas nas Tab. 3 e 4. Apenas os eqüinos da raça Pantaneira de cascos claros apresentaram maior concentração de fósforo. Os demais elementos estudados não diferiram entre si quanto à coloração dos cascos $(\mathrm{P}>0,05)$.

Tabela 3. Composição química média de matéria seca (MS), proteína bruta (PB), cinzas (Cz), extrato etéreo $(\mathrm{EE})$, cálcio $(\mathrm{Ca})$, fósforo $(\mathrm{P})$, cobre $(\mathrm{Cu})$, zinco $(\mathrm{Zn})$ e biotina dos cascos claros e pretos de eqüinos das raças Mangalarga Marchador e Pantaneira

\begin{tabular}{lccccc}
\hline \multirow{2}{*}{ Nutriente } & \multicolumn{2}{c}{ Mangalarga Marchador } & & \multicolumn{2}{c}{ Pantaneiro } \\
\cline { 2 - 3 } \cline { 5 - 5 } MS (\%) & Casco claro & Casco preto & & Casco claro & Casco preto \\
PB (\%) & 65,71 & 66,74 & & 68,36 & 68,88 \\
Cz (\%) & 96,15 & $2,0,19$ & & 96,41 & 96,34 \\
EE (\%) & 1,80 & 1,03 & 2,06 & 2,12 \\
Ca (ppm) & 0,95 & 207,15 & & 1,31 & 1,44 \\
P (ppm) & 258,24 & 186,80 & & 468,61 & 666,69 \\
Cu (ppm) & 155,40 & 4,53 & & $143,80 \mathrm{a}$ & $107,12 \mathrm{~b}$ \\
Zn (ppm) & 4,30 & 66,10 & & 19,75 & 27,37 \\
Biotina (mg/kg) & 68,22 & 0,44 & & 111,92 & 120,48 \\
\hline
\end{tabular}

Valores seguidos por letras distintas na mesma linha, para a mesma raça, diferem entre si $(\mathrm{P}<0,05)$. 
Tabela 4. Composição média de aminoácidos (\% matéria seca) de cascos claros e pretos nas raças Mangalarga Marchador e Pantaneira

\begin{tabular}{lccccc}
\hline \multirow{2}{*}{ Aminoácido } & \multicolumn{2}{c}{ Mangalarga Marchador } & & \multicolumn{2}{c}{ Pantaneiro } \\
\cline { 2 - 3 } \cline { 5 - 5 } & Casco claro & Casco preto & & Casco claro & Casco preto \\
\hline A. aspártico & 7,6720 & 7,3420 & & 7,3590 & 7,3380 \\
A. glutâmico & 15,2050 & 14,5610 & & 14,9410 & 14,8730 \\
Serina & 6,4960 & 6,1490 & & 6,3130 & 6,2590 \\
Glicina & 0,0250 & 0,0120 & & 0,0340 & 0,0230 \\
Histidina & 7,4440 & 7,0420 & & 7,4600 & 7,1078 \\
Arginina & 5,8410 & 5,4440 & & 5,9344 & 5,3567 \\
Treonina & 3,8310 & 3,5780 & & 3,6980 & 3,5980 \\
Alanina & 2,6100 & 2,6880 & & 2,6400 & 2,6410 \\
Prolina & 2,5540 & 2,1080 & & 2,3510 & 2,2390 \\
Tirosina & 6,0870 & 5,8170 & & 5,9390 & 5,8190 \\
Valina & 1,2300 & 1,0270 & & 2,2530 & 1,7150 \\
Leucina & 3,8270 & 3,8640 & & 3,3300 & 3,3530 \\
Metionina & 6,1050 & 5,9020 & & 6,0644 & 5,8556 \\
Isoleucina & 5,3680 & 5,1900 & & 5,3000 & 5,3490 \\
Cistina & 2,0829 & 4,3943 & & 5,6811 & 3,0022 \\
Fenilalanina & 4,5570 & 4,0990 & & 4,5722 & 4,0456 \\
Lisina & 2,3590 & 2,5100 & & 2,2930 & 1,8810 \\
\hline Vales
\end{tabular}

Valores na mesma linha, na mesma raça, não diferem entre si ( $\mathrm{P}>0,05)$.

Weiser et al. (1965) e Miyaki et al. (1974), citados por Butler e Hintz (1977), não encontraram diferenças na composição química dos cascos brancos e pretos, e Butler (1992) afirmou que a pigmentação do casco não interfere na resistência do casco deste.

A maior concentração de fósforo presente nos cascos claros da raça Pantaneira não encontrou respaldo na literatura consultada. Entretanto, parece que esse mineral está diretamente envolvido com a resistência do casco, pois, de acordo com Grosenbaugh e Hood (1992), o fósforo tem importante ação na formação da matéria cimentante do casco, rica em fosfolípideos, os quais unem seus envelopes protéicos. A maior concentração de fósforo nos cascos claros da raça Pantaneira pode, portanto, ser resultado de sua menor utilização. Ao contrário, a menor concentração desse mineral nos cascos pretos sugere sua maior utilização no processo de formação da matéria cimentante e, conseqüentemente, seu menor acúmulo no tecido córneo. Butler (1992) observou que a pigmentação dos cascos em um mesmo animal não interferiu na sua resistência, mas enfatizou que em animais distintos parece haver diferença. Slaater et al. (1997) afirmaram que a coloração do casco não está associada à sua resistência.

A semelhança encontrada na concentração dos aminoácidos nos cascos claros e escuros confirma os resultados de Nascimento (1999), o qual citou que cascos claros e escuros têm a mesma estrutura protéica com a mesma composição de aminoácidos.

\section{CONCLUSÕES}

Como a cor dos cascos da raça Mangalarga Marchador não apresenta diferença quanto aos elementos testados, não se justifica a preferência para uma ou outra coloração. A menor concentração de fósforo dos cascos pretos dos eqüinos da raça Pantaneira sugere sua maior utilização no processo de formação da matéria cimentante do casco e, consequentemente, seu menor acúmulo no tecido córneo.

\section{AGRADECIMENTOS}

Dr. Luciano Barros e família, proprietários da fazenda Rancharia. Dr. Agostinho Patrus e família, proprietários do Haras Luxor. Instituto Mineiro de Agropecuária. Universidade Federal de Lavras

\section{REFERÊNCIAS BIBLIOGRÁFICAS}

ASSOCIAÇÃO Brasileira dos Criadores do Cavalo Mangalarga Marchador - padrão racial (ABCCMM). Disponível em: 
$<$ www.abcmm.org.br $>$. Acessado em 26 de junho de 2003.

BUTLER, K.D. Foot care. In: EVANS , J.W. (Ed.). Horse breeding and management. Amsterdam : Elsevier, 1992. p.177-204 (World Animal Science).

BUTLER, K.D.; HINTZ, H.F. Effect of level of feed intake and gelatin supplementation on growth and quality of hoofs of ponies. J. Anim. Sci., v.44, p.257-2261, 1977.

COMBEN, N.; CLARK, R.J.; SUTHERLAND, D.J.B. Clinical observation on the response of equine hoof supplementation with biotin. Vet. Rec, v.115, p.642-645, 1984.

COSTA, M.D.; BERGMANN, J.A.G.; RESENDE, A.S.C. et al. Caracterização demográfica da raça Mangalarga Marchado. Arq. Bras. Med. Vet. Zootec., v.56, p.687-690, 2004.

CUNNIFF, P. (Ed.). Official methods of AOAC International. 16.ed. Arligton: AOAC International, 1995. v. 1.

GROSENBAUGH, D.A.; HOOD, D.M. Keratin and associated proteins of the equine hoof wall. Am. J. Vet. Res., v.53, p.1859- 1863, 1992.
NASCIMENTO, J.F. Mangalarga Marchador: tratado morfofuncional. Belo Horizonte: Associação Brasileira dos Criadores do Cavalo Mangalarga Marchador, 1999. 558p.

REZENDE, A.S.C. Raças raras da fazenda brasileira: eqüinos e asininos. Ação Ambiental, v.3, p.15-18, 2001

SLATER, M.R.; HOOD, D.M. A cross-sectional epidemiological study of equine hoof wall problems and associated factors. Equine Vet. J., v.29, p.67-69, 1997.

SPITZLEI, S. Untersuchung zur Zusammensetzung des Hufhorns beim Pferd, deren Bedeutung für die Stabilität und Beziehung zur Nährstoffversorgung (zur Erlangung des Grades eines durch die) - Aus dem Institut für Tierernährung der Tierärztlichen Hochschule Hannover, 1996.

TORRES, A. Di P.; JARDIM, W.R. Criação do cavalo e de outros eqüideos. 3.ed. São Paulo: Nobel, 1992. 1906p.

ZENKER, W.; JOSSECK, H.; GEYER, H. Histological and physical assessment of poor hoof horn quality in Lipizzaner horses and a therapeutic trial with biotin and placebo. Equine Vet. J., v.27, p.183-191, 1995. 